\title{
Corticorelin Acetate
}

National Cancer Institute

\section{Source}

National Cancer Institute. Corticorelin Acetate. NCI Thesaurus. Code C76112.

The acetate salt form of coticorelin, a synthetic peptide of neurohormone corticotropinreleasing factor (CRF), with potential antitumor and antiangiogenesis activities. Upon administration, corticorelin stimulates adrenocorticotropic hormone (ACTH) secretion from the anterior pituitary gland. In turn, ACT H stimulates cortisol production from the adrenal cortex and is regulated by a negative feedback mechanism. Corticorelin appears to inhibit swelling around brain tumors through reduction in vascular leakage and maintenance of endothelial cell integ rity. This agent potentially suppresses vascularization and tumor cell growth through reduction of vascular endothelial growth factor (VEGF) that appears to be via activation of corticotrophin-releasing factor receptor 2 (CRFR2), a G protein-coupled receptor. 